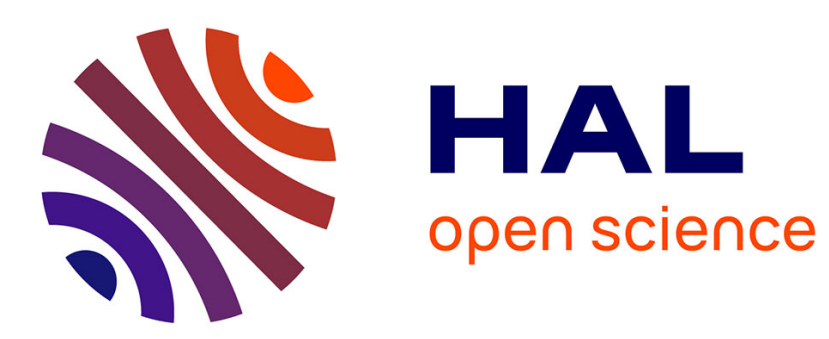

\title{
Psychological Bias and Gender Wage Gap
}

Frédéric Palomino, Eloïc-Anil Peyrache

\section{To cite this version:}

Frédéric Palomino, Eloïc-Anil Peyrache. Psychological Bias and Gender Wage Gap. Journal of Economic Behavior and Organization, 2010, 76 (3), pp.563. 10.1016/j.jebo.2010.07.004 . hal-00911836

\section{HAL Id: hal-00911836 \\ https://hal.science/hal-00911836}

Submitted on 30 Nov 2013

HAL is a multi-disciplinary open access archive for the deposit and dissemination of scientific research documents, whether they are published or not. The documents may come from teaching and research institutions in France or abroad, or from public or private research centers.
L'archive ouverte pluridisciplinaire HAL, est destinée au dépôt et à la diffusion de documents scientifiques de niveau recherche, publiés ou non, émanant des établissements d'enseignement et de recherche français ou étrangers, des laboratoires publics ou privés. 


\section{Accepted Manuscript}

Title: Psychological Bias and Gender Wage Gap

Authors: Frédéric Palomino, Eloïc-Anil Peyrache

PII: $\quad$ S0167-2681(10)00135-6

DOI: $\quad$ doi:10.1016/j.jebo.2010.07.004

Reference: $\quad$ JEBO 2576

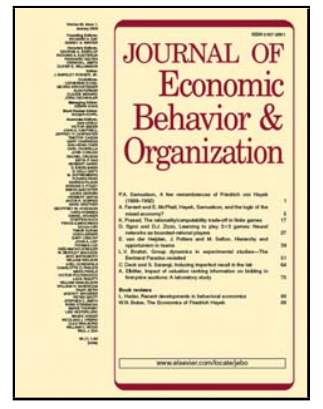

To appear in: Journal of Economic Behavior \& Organization

Received date: $\quad$ 5-2-2008

Revised date: $\quad$ 9-7-2010

Accepted date: $\quad$ 13-7-2010

Please cite this article as: Palomino, F., Peyrache, E.-A., Psychological Bias and Gender Wage Gap, Journal of Economic Behavior and Organization (2010), doi:10.1016/j.jebo.2010.07.004

This is a PDF file of an unedited manuscript that has been accepted for publication. As a service to our customers we are providing this early version of the manuscript. The manuscript will undergo copyediting, typesetting, and review of the resulting proof before it is published in its final form. Please note that during the production process errors may be discovered which could affect the content, and all legal disclaimers that apply to the journal pertain. 


\title{
Psychological Bias and Gender Wage Gap *
}

\author{
Frédéric PALOMINO ${ }^{\dagger} \quad$ Eloïc-Anil PEYRACHE \\ EDHEC HEC Paris
}

June 7, 2010

\footnotetext{
${ }^{*}$ We thank Johannes Horner for insightful discussions and Frances Sell for assistance. Correspondence to: EloïcAnil Peyrache, Department of Finance and Economics, HEC School of Management, 1 rue de la Liberation, 78351 Jouy-en-Josas Cedex, France; email: peyrache@hec.fr

${ }^{\dagger}$ EDHEC Business School, Department of Economics, 12 bis rue de la victoire 75009 Paris, France. E-mail: frederic.palomino@edhec.edu
} 


\title{
Psychological Bias and Gender Wage Gap
}

\begin{abstract}
Basing our work on the literature on psychology that highlights differences in confidencelevels between men and women, we provide a rationale for the simultaneous existence of the two dimensions of the gender wage gap: (i) on average, men earn more than women and (ii) the difference in wages depends on the gender structure. We also argue that although an equal compensation policy does not eliminate the gender wage gap, it nonetheless increases social welfare. Finally, endogenizing the choice of task by agents, we show how women, in a vast majority, can self-select on low paying jobs.
\end{abstract}

Keywords: bias, gender, optimal contract, wage gap.

JEL Classification: J16, J33, J71 


\section{Introduction}

The existence and persistence of a gender wage gap is certainly an open secret. A large number of papers have well documented the pay difference based on gender characteristics. A recent release from the Census Bureau (CENSR-15, May 2004) states that "the female-to-male earnings ratio at the median for year-round, full time workers was 77 percent in 2002". This gender wage gap is mainly bi-dimensional. The first dimension is well-known and accounts for the fact that, on average, women earn less than men (see, for example, Fields and Wolff 1995, Blau and Kahn 2000, Graddy and Pistaferri 2000). The second dimension is a group effect: the larger the fraction of woman in an industry or a job, the lower the average wage (see Johnson and Solon 1986, Reilly and Wirjanto 1999 and Boraas and Rodgers 2003). According to Boraas and Rodgers (2003), in 1999, taking into account personal characteristics, women who are employed in occupations in which they represent 90 percent of the workforce earn 19 percent less than women employed in occupations where men represent 90 percent of the workforce. The disadvantage falls to 13 and 7 percent in occupations where female represent 50 percent and 30 percent of the workforce, respectively. This suggests that not only demographic characteristics (gender, age...) are at stake but, additionally, that the composition of the group to which the employee belongs is also important.

Various explanations have been offered to justify the existence of such a gender wage gap. It is widely advocated that women's career breaks and their participation in the labor market are relevant explanation for the existence of a gender wage gap (see Corcoran and Duncan 1979, Mincer and Ofek1982, Cox 1984, Mincer and Polachek 1974 and Polachek 1981). However, many other rationales have been provided. Rothschild and Stiglitz (1982) stress differences in the noise of productivity signals across genders whereas Milgrom and Oster (1987) underline poor observability of women's quality on the external market. Other sources of the heterogeneity among genders have been analyzed such as difference in tastes (Killingsworth 1987), differences in the degree of risk aversion (Eckel and Grossman 2003), the existence of non-market benefits for women (Lazear and Rosen 1990), and a difference in commitment power in the presence of firm specific human capital accumulation (Kuhn 1993). Many authors have also pointed out some sociological explanations such as the desire by men to maintain their occupational status (Goldin 2002), the mechanics of interactions within households (François 1997 and François and Van Ours 2000) and differences in expectation regarding future wages (Filippin and Ichino 2005). However, all these models focus on the equal occupation dimension of the gender wage gap and do not consider the group effect 
dimension.

In this article, we propose a new approach which, endogenously, generates that in a cohort of equally talented agents, both aspects of the gender wage gap can emerge in equilibrium. This approach is based on two sets of empirical findings. First, following the work of Tomaskovic- Devey and Skaggs (1999), we assume that there are no real productivity differences between men and women, hence that the gender wage gap cannot be attributed to a difference of innate ability. Second, we borrow from the literature in psychology according to which it is now a well-established empirical fact that men and women differ noticeably in their level of self-confidence in many areas of achievement (see Section 2). Our guiding line is that if such differences in self-confidence have proven to be tangible in many areas, then it is of interest to study whether it could generate some gender wage gap. Illustrating our model with some data analysis would be of great value, but unfortunately having access to a data base that could match some psychological parameters of agents, the proportion of men/women on the occupation and finally their salary is a very difficult task. In this paper, we then concentrate on a first theoretical step aiming at building a bridge between empirical evidence in psychology and some stylized facts in labor markets.

We consider a standard principal-agent model in which a rational principal delegates the execution of a task to either a woman or a man. Traditionally, the main source of productivity-difference between men and women is considered to be due to the smaller amount of time and energy that women devote to their career. We depart from such an analysis and, in line with the literature in psychology, we assume that men and women are biased regarding the perception of their own productivity of effort. Whereas men over-estimate such productivity, women under-estimate it. As mentioned above, we assume that both genders have the same innate ability and, additionally, the same cost of effort. We proceed in two steps. First, we let the principal discriminate between the genders and demonstrate that only the first dimension of the wage gap can be explained. Second, we consider the case in which discrimination is banned ${ }^{1}$. We show that the unique equilibrium has the feature that the greater the probability of men applying for the job, the larger the average wage. Furthermore, because of the over-estimation of their own productivity, men exert more effort than women and then, on average, receive a higher financial compensation. The same results hold true

\footnotetext{
${ }^{1}$ As empirical evidence shows, discrimination in wages and bonuses may end up being very costly for firms. As an illustration, Merril Lynch has already paid out more than USD 100 millions to past and present female employees. See, The Economist, "Sexism and the City", June 10, 2004, for more evidence.
} 
when the choice of tasks is endogenous.

The implications of our results are twofold. First, whenever discrimination is not allowed, the optimal contract proposed by the principal is such that both dimensions of the gender wage gap are obtained. An equal compensation policy is then not sufficient to eliminate the gender wage gap. Second, conducting a welfare analysis, we show that the difference in effective average utility between women and men depends on the difference in the magnitude of the bias between men and women. Stated differently, despite a lower revenue, on average, women's surplus can be higher than men's if, for example, they assess their marginal productivity of effort accurately whereas men over-estimate it. Additionally, we show that an equal compensation policy increases social welfare. Finally, building upon our base model and endogenizing the allocation of agents on various projects, we show how, in a vast majority of cases, women self-select on low paying jobs whereas men choose high-paying jobs.

Before proceeding, we should mention that we do not pretend to capture the "full picture" about the gender wage gap, but we aim at building a bridge between the standard economic approach based on incentives and research outcomes in psychology highlighting behavioral difference between women and men. Moreover, this paper provides a first theoretical step towards highlighting group effects in the decomposition of the gender wage gap.

The organization of the paper is as follows. Section 2 reviews the literature on gender-related psychological biases. Section 3 describes the model. In Section 4 the optimal contracts in cases where discrimination is successively allowed and not allowed are derived, and welfare implications are analyzed. In Section 6 the choice of projects is endogenized. Finally, Section 7 offers a conclusion.

\section{Gender and Psychological Bias}

Gender differences in self-confidence have been extensively documented in the academic literature in psychology. Testing for the perception of competences on various tasks, Beyer (1990) shows that men tend either to be accurate or to over-estimate their ability, whereas women tend either to be accurate or to underestimate their ability. Similarly, testing differences in confidence judgement, Lundeberg, Fox and Puncochar (1994) conclude that "the problem may not be that women necessarily lack confidence but that, in some cases, men have too much confidence".

In a different vein, Babcock and Laschever (2003) advocate that, as they don't use negotiation to get what they want, women just don't ask for pay raises, promotions and better job opportu- 
nities. Deaux and Farris (1977), Meehan and Overton (1986) and Beyer (1999a) find that men have a tendency to take too much credit for their successes and, consequently, suffer from a greater self-serving attribution bias than women do. In addition, Beyer (1999b) also finds that female undergraduate students overestimate their grades less than men do. Finally, Gneezy, Niederle and Rustichini (2003) provide experimental evidence that women may be less effective in competitive environments even if they are able to perform similarly in non-competitive environments. Additionally, Gneezy, Niederle and Rustichini (2003) provide evidence that, when asked to choose the difficulty of tasks, men choose more difficult tasks relative to women.

Deaux and Farris (1977) also advocate that the gender bias is highly task-dependent by claiming that "men claim more ability than do women, but this difference emerges more strongly on masculine tasks". This is confirmed by several other studies. Prince (1993) finds that men feel more competent than women in financial matters and, as observed by Barber and Odean (2001), men are disproportionately represented in the financial industry. Beyer (2002) finds differences in self-valuation between men and women in a mathematics test (considered as a masculine task) but no difference in an English test (feminine task) and or in history and geography tests (neutral tasks). Similarly, De Keuster, Rynes and De Heers (2004) provide evidence that female undergraduate students majoring in Management Information System (a supposedly "masculine" field) under-estimate their ability to a greater extent than do male students, while Beyer, Rynes and Haller (2004) find that women have lower confidence-levels than men in their ability in computer sciences (another supposedly "masculine" field).

\section{The Basic Moral Hazard Model}

We propose a standard moral hazard type of model where an employer (the principal) delegates the realization of a project to one of his employees (the agent), who can either be a man $(m)$ or a woman $(w)$. There is a proportion $\theta$ of women and, consequently, $(1-\theta)$ of men. Both types of agents are risk neutral and subject to a limited liability constraint normalized to zero. The project generates a net return $V_{h}>0$ whenever the agent is successful and $V_{l}<0$ otherwise. We denote by $\Delta V$ the difference $V_{h}-V_{l}$. The effective probability of success on the project depends on the innate ability of the agent $(\rho)$ and an effort $e$ he/she exerts. To make the analysis as general as possible, 
we model the true probability of success as follows

$$
\text { Probability of success }=e\left(a_{1}+a_{2} \rho\right)+a_{3} \rho \quad i=m, w
$$

where $a_{1}, a_{2}$ and $a_{3}$ are positive parameters weighting the impact of effort and ability in the probability of success. ${ }^{2}$ In the rest of the paper, it is assumed that $a_{1}+a_{2}>0$. Otherwise, the probability of success would be independent of the effort exerted.

Agents are uniquely differentiated according to their gender characteristics. Following a large body of literature in psychology, men are assumed to over-estimate their probability of being successful on a project whereas women are assumed to under-estimate it. Formally, we account for such psychological effect by defining bias parameters $k_{m} \geq 1$ and $k_{w} \leq 1$, for men and women respectively, and modelling their perceived probability of success as follows

$$
p\left(e_{i}, k_{i}\right)=k_{i} e_{i}\left(a_{1}+a_{2} \rho\right)+a_{3} \rho \quad i=m, w
$$

That is, we focus on a setting where the bias impacts agents' marginal productivity of effort. Effort is costly and is given by $C(e)=c \frac{e^{2}}{2}$ with $c>0$ for both types of agents. ${ }^{3}$

As is shown in the next section, as a result of this modelling of overconfidence, men exert more effort than women in equilibrium and, under the conditions provided in footnote 3 , the equilibrium probability of success is strictly smaller than 1 . One could certainly have a different interpretation of the psychology literature on overconfidence, namely that men overestimate their innate ability rather than their productivity of effort. Such analysis would suggest a scenario of the type "I am so good that I can succeed without exerting much effort". However, for such a scenario to lead to men exerting less effort than women in equilibrium, it must be the case that men believe they will succeed with probability 1 at the optimal (i.e., utility maximizing) effort level. This form of overconfidence appears very extreme and does not fit in a richer (and more realistic setup) in which agents tackle several project successively and learning takes place (as will be discussed in Section 7) since at their first failure, agents would realize that they are overconfident. As a consequence, we have chosen to rule this extreme type of overconfidence out. This does not mean that we discard

\footnotetext{
${ }^{2}$ Adding a white noise, as is often modelled in the literature, would not alter our result and would not bring any additional insight.

${ }^{3}$ Assuming that $\frac{\Delta V}{c} \in\left(\frac{a_{3} \rho}{\left(a_{1}+a_{2} \rho\right) k_{w}}, \frac{2\left(1-a_{3} \rho\right)}{\left(a_{1}+a_{2} \rho\right)^{2} k_{m}}\right)$ ensures that the principal is willing to undertake the project, and that in all cases the equilibrium probability of success is strictly smaller than 1 . The above interval is non empty as long as $\rho$ is small enough.
} 
the case in which men overestimate both the innate ability and their productivity of effort, this case being addressed is Section 4.2. However, we will still focus on sets of parameters such that the equilibrium probability of success is strictly smaller than 1 .

Finally, as it is standard in contract theory, we assume that effort is not observable and, therefore, cannot be contracted upon. Finally, the principal has all the bargaining power and makes a takeit-or-leave-it offer to the agent.

To summarize, we consider a game with the following timing. The principal first makes a takeit-or-leave-it offer to the agent. The latter then accepts or refuses the contract. If he/she refuses, the game ends and all parties get 0 . If he/she accepts the contract, he/she chooses a corresponding level of effort. Then, the output is realized and the agent receives transfers accordingly.

\section{Contract Design}

We start by describing the optimal contract in a setting where discrimination is either allowed or banned. We then consider welfare aspects.

\subsection{Optimal Contract}

As is standard in models of moral hazard, the agent must be given incentives to exert effort. In the previous section, we have described the simplest model that allows for such a structure. Given that effort is not contractible, the principal provides incentives by conditioning the reward scheme on the outcome of the project which is both observable and enforceable. Denote $q$ such an outcome. Given the two-point distribution of the project value, we define a compensation contract conditioning the reward on the realized project value as follows.

$$
h(\alpha, \beta, q)=\left\{\begin{array}{lll}
\alpha & \text { if } & q=V_{l} \\
\beta & \text { if } & q=V_{h}
\end{array}\right.
$$

with $\alpha<\beta$. One can naturally think of bonus reward schemes as being described by such a binary outcome model but it also accounts for standard "promotion" incentive schemes or "up or out contracts" settings. ${ }^{4}$

We solve the model by backward induction. Taking the contract offered by the principal as given,

\footnotetext{
${ }^{4}$ We discuss the robustness of our approach to other incentive schemes later in the paper.
} 
an agent $i$ with a bias parameter of magnitude $k_{i}$ performs an effort

$$
e\left(k_{i}, \alpha_{i}, \beta_{i}\right)=\frac{k_{i}}{c}\left(a_{1}+a_{2} \rho\right)\left(\beta_{i}-\alpha_{i}\right)
$$

It directly follows from the difference in perception of marginal productivity between men and women (i.e., $k_{m}>k_{w}$ ) that, for a given contract, men exert more effort than women.

We can distinguish two (legal) environments under which the principal offers his contract. In the first one, the principal is free to discriminate among agents, while in the second the principal is constrained to offer the same (menu of) contract(s). The next propositions derive the optimal contract in each setting.

Proposition 1 If the principal can discriminate among gender, then the optimal contract is

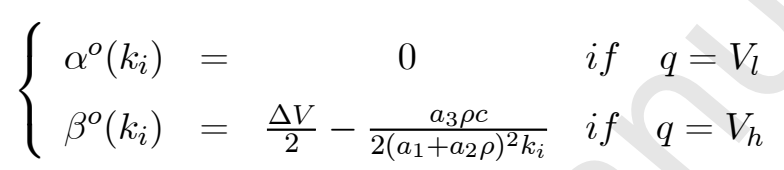

Proof. The proof is straightforward. Rationally anticipating the effort of the agent in the continuation game, the objective of the principal is, for each gender, to maximize

$$
F(\alpha, \beta, k)=V_{l}-\alpha+p\left(e_{i}\left(k_{i}, \alpha, \beta\right), 1\right)(\Delta V-\beta+\alpha)
$$

subject to $\alpha \geq 0$ and $\beta \geq 0$. The solution then follows directly.

Since $k_{m}>k_{w}$, we have $\beta^{o}\left(k_{m}\right)>\beta^{o}\left(k_{w}\right)$. As a result, men exert more effort than women, succeed more often and get a higher prize in case of success. However, the group effect dimension of the wage gap is left unexplained.

Let us now turn to the optimal contract when compensation discrimination is not allowed. In the rest of the paper, we will denote by $X(\theta) \equiv \theta k_{w}+(1-\theta) k_{m}$. We have the following result.

Proposition 2 When discrimination is not allowed, the unique equilibrium is pooling and, for all $i$, is such that

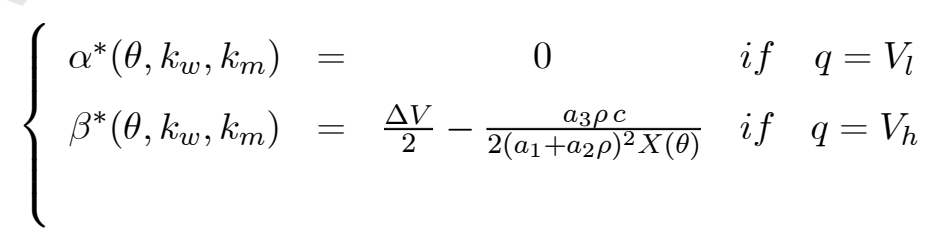

The fact that the equilibrium is pooling stems from two opposite forces. On the one hand, the principal would like to tailor contract to agents. However, to do so, he would have to pay some fixed fee $\left(\alpha_{w}\right)$ to women and choose an incentive component larger for men than for women (i.e., 
$\beta_{m}-\alpha_{m}>\beta_{w}-\alpha_{w}$ ), so that each gender self-select on each contract. There are then two costs associated to a separating equilibrium: first, rewarding women in case of failure and, second, a lower effort level chosen by women hence a lower probability of success. The proposition states that these costs exceed the benefits of a separating equilibrium (i.e., contracts tailored to agents).

Note also that the assumption of limited liability plays an important role in the derivation of this result. It implies that the participation constrain of the agents are slack. In a setting where the principal could set arbitrarily large negative wages in the event of a poor output realization, then there would be scope for separating contracts in which participation constraints are binding. In addition, a necessary condition for our result to hold is that the probability of success can be positive even in the absence of effort (namely, $a_{3}>0$ ). This is a usual assumption that can be defended on different grounds. First, innate ability is a component that does not only affect the marginal productivity of effort. Second, one can also reinterpret our model as a setting where some minimum effort (given by $a_{3} \rho$ ) can be monitored by the principal and that the contract is design to provide incentives for additional effort exertion. In the rest of the analysis, we will assume that $a_{3}>0$. A remaining question then concerns the impact of outside opportunities on the viability of our result. This is discussed in the following section on robustness.

A closer look at the optimal contract helps us to deepen our analysis of the difference in expected revenue between men and women. The reward in case of success, i.e., $\beta^{*}\left(\theta, k_{w}, k_{m}\right)$ can be rewritten as

$$
\begin{aligned}
\beta^{*}\left(\theta, k_{w}, k_{m}\right) & =\frac{\theta k_{w}}{X(\theta)} \beta^{o}\left(k_{w}\right)+\frac{(1-\theta) k_{m}}{X(\theta)} \beta^{o}\left(k_{m}\right) \\
& =\beta^{o}\left(k_{w}\right)+\frac{(1-\theta) k_{m}}{X(\theta)}\left(\beta^{o}\left(k_{m}\right)-\beta^{o}\left(k_{w}\right)\right)
\end{aligned}
$$

where $\beta^{o}\left(k_{i}\right)(i=m, w)$ is the payment in case of success when discrimination is allowed (See proposition 1). We then obtain the following result

Corollary 1 When discrimination is banned, the optimal contract is such that:

(i) men's average revenue is larger than women's one.

(ii) the larger the fraction of men (i.e., the lower $\theta$ ), the higher women's average revenue.

An equal opportunity regulation implies that men and women obtain the same compensation contract. However, this does not necessarily imply that they have the same chance of receiving a bonus or being promoted. First, due to their bias toward over-estimating their productivity, men 
exert more effort than women (see equation 1) and, therefore, receive the payment $\beta$ more often (point $(i)$ ). This is in line with the empirical observation in Puri and Robinson (2005) who present a large-scale micro level evidence linking optimism to a series of significant work related choices and show that more optimistic agents (regardless of their employment status) work harder. Moreover, it is acknowledged that women work fewer hours (BLS Bulletin 2340; US Bureau of the Census, 2000). Second, the larger the proportion of women in the industry, the lower is $\beta$. This effect drives the result in point $(i i)$.

Finally, measuring the absolute wage gap by the difference in average wages received by men and women and the relative wage gap by the ratio of average wage of men to average wage of women, additional testable implications can be derived from our model:

Corollary 2 When discriminatory conducts are banned, both absolute and relative expected wage gap increase with the proportion of men in the considered occupation.

The proof is straighforward once noting that both the absolute and the relative expected wage gap between men and women are given by $\left(a_{1}+a_{2} \rho\right)^{2} \frac{\beta^{2}}{c}\left(k_{m}-k_{w}\right)$ and $\frac{a_{3} \rho c+\left(a_{1}+a_{2} \rho\right)^{2} k_{m} \beta}{a_{3} \rho c+\left(a_{1}+a_{2} \rho\right)^{2} k_{w} \beta}$, respectively.

\subsection{Robustness of the results}

We now aim at analyzing the impact on our results of several assumptions made in the core of the paper, namely the fact that reservation utilities are normalized to zero for both genders, agents are risk neutral and, finally, the fact that psychological biases are associated to effort rather than ability.

First, our results remain valid in a framework where genders have different outside options as long as we keep on assuming that women accept the contract offered when discrimination is allowed. Suppose indeed that, for various sociological or economical reasons, women have a higher value than outside work (see Gronau 1973a, 1973b), i.e., $u_{w}^{o}>u_{m}^{o}=0$ and, additionally, that $u\left(\beta^{0}\left(k_{w}\right)\right)>u_{w}^{o}$. Given that, (i) for all $\theta>0, \beta^{*}\left(\theta, k_{w}, k_{m}\right)>\beta^{0}\left(k_{w}\right)$ and (ii) women's utility increases with the magnitude of the transfer $\beta$, then women's participation constraint is necessarily slack and the contract described in Proposition 2 remains optimal.

Second, we have assumed that men overestimate their marginal productivity whereas women underestimate it. However, some studies in the field of psychology suggest that both men and women tend to overestimate their probability of success but men to a larger extent than women. 
Our results carry over under this assumption, since our results rely on men being more overconfident than women. The gender wage gap is generated by the fact that there exists a gap between these biases. The fact that the equilibrium is uniquely pooling whenever equal treatment is imposed is key to explaining the second result of corollary 1.

An interesting argument sometimes advocated when comparing men and women's performances is that the women are more risk averse (see Eckel and Grossman (2003)). We could account for differences in preferences in our model and show that if the difference in risk-aversion between genders is not too large, then our results hold. Otherwise, agents could self-select on different contracts but the group effect of wage inequality would not emerge at equilibrium.

Finally, let us discuss the way psychological biases influence the probability of success in our model. As already mentioned, one could certainly reinterpret the results derived in the psychology literature as evidence that men overestimate their innate ability, from $\rho$ to $k_{m} \rho$, rather than their marginal productivity of effort. For example, it can be assumed that the probability of success is

$$
p\left(e, k_{i}\right)=e\left(a_{1}+a_{2} k_{i} \rho\right)+a_{3} k_{i} \rho
$$

In such a case, if discrimination is not allowed, we still obtain that the unique equilibrium is pooling and

$$
\beta\left(\theta, k_{w}, k_{m}\right)=\frac{\Delta V}{2}-\frac{a_{3} \rho c X(\theta)}{2\left[a_{1}^{2}+2 a_{1} a_{2} \rho X(\theta)+a_{2}^{2} \rho^{2}\left(\theta k_{w}^{2}+(1-\theta) k_{m}^{2}\right)\right]}
$$

It can be shown that if $a_{1}$ is small enough, then $\beta\left(\theta, k_{w}, k_{m}\right)$ is decreasing in $\theta$. In such a case, the results obtained in the case in which biases are related to effort only, still hold in the case in which biases are related to the innate ability.

\section{$5 \quad$ Welfare implications}

The implementation of an equal compensation regulation influences both workers' welfare and the level of social welfare. This influence is twofold. First, following an increase in revenue in case of good performances, women's effort and surplus increase. Second, men's revenue in case of good performances decrease. As a consequence, their effort also decreases. However, the total impact on their average realized welfare level is ambiguous. To see this, note that for a contract paying $\beta$ in 
case of success, women's and men's average realized utility ${ }^{5}$ is given by

$$
U_{i}(\beta)=\beta\left(a_{3} \rho+\left(a_{1}+a_{2} \rho\right)^{2} \frac{k_{i} \beta}{c}\left(1-\frac{k_{i}}{2}\right)\right) \quad i=m, w .
$$

It is a routine matter to check that $U_{w}$ is an increasing function of $\beta$. Given that $\beta^{*}\left(\theta, k_{w}, k_{m}\right)>$ $\beta^{o}\left(k_{w}\right)$, women's surplus then increases with the implementation of an equal compensation policy. Regarding men, a direct effect is of an equal compensation policy regulation is to decrease $\beta$. However, as a positive implication of a downgraded bonus, the over-optimal effort level decreases. Formally, there exists $\bar{k}>1$ such that $\partial U_{m}(\beta) / \partial \beta>0($ resp. $<0)$ whenever $k_{m}<\bar{k}$ (resp. $>\bar{k}$ ). The larger the salary in the case of good performance the more men exert effort. If the magnitude of the bias is large, then a decrease in $\beta$ generates a large decrease of the effort level, and the effort cost reduction dominates the expected salary reduction. On the contrary, if the bias is small, the decrease in effort level generated by a decrease in $\beta$ is small, and the expected salary reduction dominates the effort cost reduction.

In the absence of discrimination, men and women receive the same salary $\beta^{*}\left(\theta, k_{w}, k_{m}\right)$ in the case of good performance. The workers' average surplus is given by

$$
U^{N D}=\theta U_{w}\left(\beta^{*}\left(\theta, k_{w}, k_{m}\right)\right)+(1-\theta) U_{m}\left(\beta^{*}\left(\theta, k_{w}, k_{m}\right)\right)
$$

We can then provide the following results

Proposition 3 If compensation discrimination is banned, the difference in average realized utility between women and men depends on the difference in the magnitude of the bias, i.e., $\left(k_{m}-1\right)-$ $\left(1-k_{w}\right)$.

The proof is straightforward once observing that the difference in average realized utility between women and men is given by

$$
U_{w}\left(\beta^{*}\left(\theta, k_{w}, k_{m}\right)\right)-U_{m}\left(\beta^{*}\left(\theta, k_{w}, k_{m}\right)\right)=\frac{\beta^{* 2}\left(\theta, k_{w}, k_{m}\right)}{c}\left(a_{1}+a_{2} \rho\right)^{2}\left(k_{m}-k_{w}\right) \frac{\left(k_{m}-1\right)-\left(1-k_{w}\right)}{2}
$$

which sign is that of the difference $\left(k_{m}-1\right)-\left(1-k_{w}\right)$. That is, the agent with the higher average realized utility is the one endowed with the smaller bias.

\footnotetext{
${ }^{5}$ If we consider a large population, the average realized utility is equal to the expected revenue net of effort cost given the true probability distributions.
} 
Let us turn now to the level of social welfare which we measure by the wealth created net of effort cost. Under discriminatory conduct, the level of social welfare corresponds to

$$
S W^{D}=V_{l}+a_{3} \rho \Delta V+\left(a_{1}+a_{2} \rho\right)^{2}\left[\theta k_{w} \frac{\beta^{o}\left(k_{w}\right)}{c}\left(\Delta V-\frac{k_{w} \beta^{o}\left(k_{w}\right)}{2}\right)+(1-\theta) k_{m} \frac{\beta^{o}\left(k_{m}\right)}{c}\left(\Delta V-\frac{k_{m} \beta^{o}\left(k_{m}\right)}{2}\right)\right]
$$

In absence of compensation discrimination, the level of social welfare is

$$
S W^{N D}=V_{l}+a_{3} \rho \Delta V+\left(a_{1}+a_{2} \rho\right)^{2}\left[X(\theta) \frac{\beta^{*}\left(\theta, k_{w}, k_{m}\right)}{c} \Delta V-\frac{\beta^{* 2}\left(\theta, k_{w}, k_{m}\right)}{c}\left(\theta k_{w}^{2}+(1-\theta) k_{m}^{2}\right)\right]
$$

We then get that

$$
S W^{N D}-S W^{D}=\left(a_{1}+a_{2} \rho\right)^{2}\left[\frac{a_{3} \rho c}{2 X(\theta)} \theta(1-\theta)\left(k_{w}-k_{m}\right)^{2}\left(\Delta V-\frac{a_{3} \rho c}{2 X(\theta)}\right)\right]>0 .
$$

This result is summarized in the next proposition.

Proposition 4 An equal compensation policy increases the level of social welfare.

This result is not perfectly intuitive in the first place. Relying on a single contract when facing heterogenous agents should decrease the principal's profit. However, given that $\beta^{*}\left(\theta, k_{w}, k_{m}\right) \in$ $\left(\beta^{*}\left(k_{w}\right), \beta^{*}\left(k_{m}\right)\right)$, an equal opportunity treatment lowers the effort exerted by men (who have a tendency to overwork) whereas it increases effort by women (who have a tendency to under-work). Globally, social welfare increases.

\section{Endogenous Choice of Projects}

So far, we have assumed that the fraction of men and women for a given job was exogenous. However, as mentioned in Section 2, Deaux and Farris (1977) advocate that the gender bias is highly task dependent. Some later contributions such as Lundeberg, Fox and Puncochar (1994) and Beyer and Bowden (1997) confirm such an analysis. Following these pieces of evidence, we consider now the case in which there are tasks for which men and women accurately perceive their productivity and others in which they differ in their perceived productivity. Furthermore, agents non-cooperatively choose which type of task they dedicate to.

Formally, we assume that there are two projects $(A$ and $B)$. Each project generates a value $V_{h}>0$ in case of success and $V_{l}<0$ in case of failure. On project $A$, men and women accurately perceive their productivity of effort: $k_{w}^{A}=k_{m}^{A}=1$. Conversely, on project $B$, men over-estimate their productivity (i.e., $k_{m}^{B}>1$ ) while women under-estimate it (i.e., $k_{w}^{B}<1$ ). Finally, without loss 
of generality, we assume that there is a continuum of length 1 of agents, half of them being women and the rest being men.

The sequence of events is the following. First, agents choose a project. Then, the owner of project $j(j=A, B)$ makes a take-it-or-leave-it offer to each agent that has chosen project $j$. If an agent rejects the offer, he/she receives his/her reservation utility. He/she does not have the possibility to apply for a job on the other type of project.

Suppose that discrimination is not allowed, and denote $\theta_{j}(j=A, B)$ the anticipated fraction of women among agents working on project $j$. Furthermore, let $\beta_{j}\left(\theta_{j}\right)$ be the payment received in case of success on a project $j$ if women represent a fraction $\theta_{j}$ of agents anticipated to work on this project. Then, from Proposition 2, we deduce that the principals choose

$$
\alpha_{j}=0 \quad \beta^{*}\left(\theta_{j}, k_{m}^{j}, k_{w}^{j}\right)=\frac{\Delta V}{2}-\frac{a_{3} \rho c}{2\left(a_{1}+a_{2} \rho\right)^{2}\left(\theta_{j} k_{w}^{j}+\left(1-\theta_{j}\right) k_{m}^{j}\right)}
$$

Denote $\hat{U}_{w}^{N D}\left(\theta, k_{m}, k_{w}\right)$ and $\hat{U}_{m}^{N D}\left(\theta, k_{m}, k_{w}\right)$ women's and men's expected perceived surplus, respectively, for a project in which a fraction $\theta$ of agents are women, and the perceived probabilities of success of men and women are $p\left(e, k_{m}\right)$ and $p\left(e, k_{w}\right)$, respectively. Hence,

$$
\hat{U}_{w}^{N D}\left(\theta, k_{m}, k_{w}\right)=\beta^{*}\left(\theta, k_{m}, k_{w}\right)\left(a_{3} \rho+\frac{k_{w}^{2}}{2 c}\left(a_{1}+a_{2} \rho\right)^{2} \beta^{*}\left(\theta, k_{m}, k_{w}\right)\right)
$$

and

$$
\hat{U}_{m}^{N D}\left(\theta, k_{m}, k_{w}\right)=\beta^{*}\left(\theta, k_{m}, k_{w}\right)\left(a_{3} \rho+\frac{k_{m}^{2}}{2 c}\left(a_{1}+a_{2} \rho\right)^{2} \beta^{*}\left(\theta, k_{m}, k_{w}\right)\right)
$$

An equilibrium is then a pair $\left(\theta_{A}^{*}, \theta_{B}^{*}\right)$ such that the contract proposed are $\left(0, \beta^{*}\left(\theta_{A}^{*}, k_{m}^{A}, k_{w}^{A}\right)\right)$ and $\left(0, \beta\left(\theta_{B}^{*}, k_{m}^{B}, k_{w}^{B}\right)\right)$ and, for $\left(j, j^{\prime}=A, B, j^{\prime} \neq j\right)$, we have

- If $\theta_{j}^{*} \in(0,1)$ and If $\theta_{j^{\prime}}^{*} \in(0,1)$ then $\left\{\begin{array}{l}\hat{U}_{w}^{N D}\left(\theta_{j}^{*}, k_{m}^{j}, k_{w}^{j}\right)=\hat{U}_{w}^{N D}\left(\theta_{j^{\prime}}^{*}, k_{m}^{j^{\prime}}, k_{w}^{j^{\prime}}\right) \\ \hat{U}_{w}^{N D}\left(\theta_{j}^{*}, k_{m}^{j}, k_{w}^{j}\right)=\hat{U}_{w}^{N D}\left(\theta_{j^{\prime}}^{*}, k_{m}^{j^{\prime}}, k_{w}^{j^{\prime}}\right)\end{array}\right.$

- If $\theta_{j}^{*}=1$ and $\theta_{j^{\prime}}^{*}=0$ then $\left\{\begin{array}{l}\hat{U}_{w}^{N D}\left(1, k_{m}^{j}, k_{w}^{j}\right) \geq \hat{U}_{w}^{N D}\left(0, k_{m}^{j^{\prime}}, k_{w}^{j^{\prime}}\right) \\ \hat{U}_{m}^{N D}\left(1, k_{m}^{j}, k_{w}^{j}\right) \leq \hat{U}_{m}^{N D}\left(0, k_{m}^{j^{\prime}}, k_{w}^{j^{\prime}}\right)\end{array}\right.$

- If $\theta_{j}^{*} \in(0,1)$ and $\theta_{j^{\prime}}^{*}=0$ then $\left\{\begin{array}{l}\hat{U}_{w}^{N D}\left(\theta_{j}^{*}, k_{m}^{j}, k_{w}^{j}\right) \geq \hat{U}_{w}^{N D}\left(0, k_{m}^{j^{\prime}}, k_{w}^{j^{\prime}}\right) \\ \hat{U}_{m}^{N D}\left(\theta_{j}^{*}, k_{m}^{j}, k_{w}^{j}\right)=\hat{U}_{m}^{N D}\left(0, k_{m}^{j^{\prime}}, k_{w}^{j^{\prime}}\right)\end{array}\right.$

- If $\theta_{j}^{*} \in(0,1)$ and $\theta_{j^{\prime}}^{*}=1$ then $\left\{\begin{array}{l}\hat{U}_{w}^{N D}\left(\theta_{j}^{*}, k_{m}^{j}, k_{w}^{j}\right)=\hat{U}_{w}^{N D}\left(1, k_{m}^{j^{\prime}}, k_{w}^{j^{\prime}}\right) \\ \hat{U}_{m}^{N D}\left(\theta_{j}^{*}, k_{m}^{j}, k_{w}^{j}\right) \geq \hat{U}_{m}^{N D}\left(1, k_{m}^{j^{\prime}}, k_{w}^{j^{\prime}}\right)\end{array}\right.$ 
Therefore, an equilibrium is a situation in which 1) principals choose contracts according to their beliefs $\left.\theta_{j}^{*}(j=A, B), 2\right)$ agents choose their task so as to maximize their expected perceived surplus given the contracts chosen by principals, and 3) the fraction of women among agents working on project $j(j=A, B)$ is effectively $\theta_{j}^{*}$.

The following proposition derives the fraction of women involved on projects $A$ and $B$.

Proposition 5 Men only work on project B. There exist functions $G\left(k_{m}\right)$ and $H\left(k_{m}\right)$ (with $H\left(k_{m}\right)>G\left(k_{m}\right)$ for all $\left.k_{m}>1\right)$ such that

(i) If $k_{w}^{B} \leq G\left(k_{m}^{B}\right)$, then women only work on project $A$, i.e., $\theta_{A}^{*}=1$ and $\theta_{B}^{*}=0$.

(ii) If $k_{w}^{B} \in\left(G\left(k_{m}^{B}\right), H\left(k_{m}^{B}\right)\right)$, then women work on both project, i.e., $\theta_{A}^{*}=1$ and $\theta_{B}^{*} \in(0,1 / 2)$.

(iii) If $k_{w}^{B} \geq H\left(k_{m}^{B}\right)$, then women only work on project $B$, i.e., $\theta_{B}^{*}=1 / 2$ and nobody works on project $A$.

The proposition characterizes the equilibrium for all sets of parameters. In part (i), women and men self-select on two different jobs and men earn, on average, more than women. However, the group effect of the gender wage gap is absent. Part (ii) and (iii) are certainly the most interesting ones since they establish that the two dimensions of the gender wage gap may arise endogenously when agents choose between several tasks for which they have different perceived productivity. In part (ii), the proportion of women choosing project B, in equilibrium, is determined such that women are indifferent between both projects. Their perceived utilities are then identical on both projects. Nevertheless, it is a routine matter to show that the average revenue of agents working on project $\mathrm{B}$ is larger than that of agents working on project $\mathrm{A}$ and, additionally that the average revenue of men (working on project B) is larger than that of women working on project B. Finally, part (iii) is very similar to the analysis of the base model and the same conclusions carry on.

The proposition also states that men always choose the job for which they feel more competent. This is consistent, for example, with results concerning the finance industry: men generally feel more competent than women do in financial matters (See Prince 1993) and, as stated by Barber and Odean (2001) "casual observation reveals that men are disproportionately represented in the finance industry". Another interesting feature of Proposition 5 is that women can dedicate themselves to project $\mathrm{A}$ which, in our model, can de denominated as the low paying job $\left(\beta_{A}<\beta_{B}\right)$. Two effects explain why women may self-select on low pay jobs, rather than choosing high pay jobs. On the one hand, both genders would like to choose project $B$ since the transfer received in case of success is larger for project B than for project A. On the other hand, if women feel less able to perform such 
a task (i.e., $k_{w}^{B}<1$ ), they believe that their probability of success is low. If this bias is sufficiently high (i.e., $k_{w}^{B}<G\left(k_{m}^{B}\right)$ ), the second effect is stronger than the first one and men and women choose different projects. As the bias weakens (i.e., $\left.k_{w}^{B} \in\left(G\left(k_{m}^{B}\right), H\left(k_{m}^{B}\right)\right)\right)$ women's incentives to choose project B increase and women split on the two projects. Still, they tend to work in occupation where their gender is highly represented. This is in line with empirical finding since, as stated by O'Neill (2003), "In 2001 women, on average, worked in occupations in which the percentage of female employees was close to 68 percent; men worked in occupations that were only 30 percent female."

The previous analysis assumes that employees choose their job. Consider now the case in which a principal has to find a worker for a project $B$ (i.e., a project about which women underestimate their productivity and men overestimate theirs) and that there are two applicants, a man and a woman. If men and women have the same ability then the man is the one hired by the principal since his profit is increasing in self-perceived productivity. Furthermore, allowing for different levels of ability, a woman must be endowed with greater ability than a man in order to be chosen by the principal.

\section{Discussion and Concluding Remarks}

It is now well established that men and women differ in their confidence levels although such empirical results have not been used in a personnel economics perspective. Building upon this observation and using a mechanism design approach, we have shown that contract theory provides a useful framework to highlight how the two dimensions of the gender wage gap, namely the traditional dimension and the group-effect dimension, can emerge at equilibrium. Furthermore, we have derived additional testable implications, such as the increase of both absolute and relative wage gap with the proportion of men in an occupation.

A consequence of our results is that an equal-opportunity policy will not eliminate the gender wage gap. In our framework, as long as biases are effectively at stake, women always earn less than men. However, the sign of the difference in surplus is ambiguous and stems from the fact that both genders do not necessarily choose the optimal amount of effort. Although women have a tendency to under-work, men have a tendency to over-work. The fact that an equal-compensation regulation does not eliminate the gender wage gap does not imply that such regulation should be re-evaluated. 
As we also show, an equal-compensation policy increases social welfare.

The forces underlying our results easily extend to different incentives schemes and production technologies. Consider for example that agents effectively produce goods in quantity (or quality) $q_{i}=\left(a_{1}+a_{2} \rho^{\prime}\right) e_{i}+a_{3} \rho^{\prime}+\epsilon_{i}$, where $\epsilon_{i}$ is a white noise. Each unit has a value $\Delta V$ for the principal and he offers $w_{i}$ for each unit produced by gender $i$. It can be shown that the contract offered by the principal is exactly the same as the one described earlier in the sense that the reward scheme is such that $w_{i}=\beta^{o}\left(k_{i}\right)$ whenever the principal can discriminate, and $w(\theta)=\beta^{*}\left(\theta, k_{w}, k_{m}\right)$, otherwise. The wage gap highlighted in this setup is then not based on the average revenue but, in contrast, on the effective revenue.

Our behavioural-economics approach can also provide a useful theoretical framework compatible with a growing literature stating that women are less competitive than men (Niederle and Vesterlund 2005 or Gneezy, Niederle and Rustichini 2004). An important difference between these studies and our model, apart from the fact that these papers are experimental, is that they consider contests with exogenously given prizes and test behavioral differences among genders whereas we start from the stylized fact that there exist behavioral differences among men and women and we endogenously determine the optimal reward scheme. Even in our framework where agents are not rewarded on the relative performance, we show that the expected utility derived by each party depends on his identity and the proportion of the respective genders in the pool.

Formally, consider that agents are not paid solely according to their own performance but rather enter a contest. Whenever facing a man, the expected probability of success of a woman is denoted $P_{m}^{w}$ and is given by

$$
\begin{aligned}
P_{m}^{w} & =\operatorname{Pr}\left(a_{3} \rho+\left(a_{1}+a_{2} \rho\right) k_{w} e_{w}+\epsilon_{w}>a_{3} \rho+\left(a_{1}+a_{2} \rho\right) k_{m} e_{m}+\epsilon_{m}\right) \\
& =\operatorname{Pr}\left(k_{w} e_{w}-k_{m} e_{m}>\eta\right) \equiv G\left(k_{w} e_{w}-k_{m} e_{m}\right)
\end{aligned}
$$

where $\eta=\left(\epsilon_{m}-\epsilon_{w}\right) /\left(a_{1}+a_{2} \rho\right)$ and $G($.$) is the distribution function of \eta$. To keep things simple, assume that $G($.$) is twice differentiable and denote g($.$) the density function associated to G($.$) .$ Furthermore, assume that $g($.$) is symmetric and single-peaked at 0$. Denote $B>0$ the prize for the winner. Women then choose their effort level such that

$$
g\left(k_{w} e_{w}^{*}-k_{m} e_{m}^{*}\right) k_{w} B=c e_{w}^{*}
$$

whereas men act as follows

$$
g\left(k_{m} e_{m}^{*}-k_{w} e_{w}^{*}\right) k_{m} B=c e_{m}^{*}
$$


Given that the function $g($.$) is symmetric and single-peaked in 0$, we have $g\left(k_{m} e_{m}^{*}-k_{w} e_{w}^{*}\right)=$ $g\left(k_{w} e_{w}^{*}-k_{m} e_{m}^{*}\right)$. Hence, men choose a higher effort level than women $\left(e_{m}^{*}=\frac{k_{m}}{k_{w}} e_{w}^{*}\right)$ and, consequently, have a higher performance level. Their chances to succeed in the contest are then higher.

To summarize, in the specific framework of a contest, the assumption that men and women overestimate and underestimate their productivity, respectively, provides then a rationale for the fact that women under-perform men in a contest (see Gneezy, Niederle and Rustichini 2003) and, relatedly, women prefer individual rather than relative pay schemes (when men are in the pool) (see Niederle and Vesterlund 2007).

Finally, we based our analysis on the fact that agents misperceive their true marginal productivity of effort and, consequently, take sub-optimal decisions. Such a statement can however become problematic in the long run since, whenever endowed with a minimum of rationality, agents should revise their perceived marginal impact of effort based on their performance record. To see that learning does not eliminate the gender wage gap, consider a model of promotion in which agents are promoted based on the number of successes on several projects they tackle, and wage increases are associated to promotions. In such a framework, updating their beliefs in a Bayesian fashion, agents will realize that for a given effort level $e_{i}$, their frequency of success is $p\left(e_{i}, 1\right)$ and not $p\left(e_{i}, k_{i}\right)$. Hence, agents should revise their effort level accordingly. However, if early in their career men and women have beliefs about their productivity such that $k_{m}>k_{w}$, this has two implications. First, early in their career, men exert more effort than women. As a consequence, their performance is greater than that of women (see Corollary 1) and their success rate is higher. Consequently, men get "promoted" faster, implying that they work on projects of higher value (and higher difference in value between success and failure, i.e., $\Delta V$ ). Hence men's revenues increase faster than those of women. Second, through their record of successes and failures men and women learn their true marginal productivity. As a consequence, after learning has taken place, men and women are not biased anymore. Everything else being equal, this implies that they would have the same rate of success. Still, a wage gap remains through out the working life cycle due to differences in performance, which implied faster promotion pace, early in the career. 


\section{Appendix}

\section{Proof of Proposition 2}

To derive the proof, we start by showing that the equilibrium is pooling. To do so, we proceed by contradiction, and assume that the principal offers two different contracts $\left(\alpha_{w}, \beta_{w}\right)$ and $\left(\alpha_{m}, \beta_{m}\right)$, with $\alpha_{w} \neq \alpha_{m}$ and $\beta_{w} \neq \beta_{m}$, that are chosen by women and men respectively. We proceed in different steps.

Lemma 1 If a separating equilibrium exists, it has to be such that only $\alpha_{m}$ is set to 0.

Assume that both $\alpha_{m}$ and $\alpha_{w}$ are strictly positive, then the principal could gain by lowering all transfers without affecting incentives. Moreover, there cannot exist a separating equilibrium where $\alpha_{w}=\alpha_{m}=0$ and $\beta_{m} \neq \beta_{w}$ since both genders would always choose the contract with the higher $\beta$.

Suppose now that $\alpha_{w}=0$ and $\alpha_{m}>0$. Then $\beta_{w}>\beta_{m}$ otherwise both agents choose $\left(\alpha_{m}, \beta_{m}\right)$. But then if women indeed choose $\left(\alpha_{w}, \beta_{w}\right)$ over $\left(\alpha_{m}, \beta_{m}\right)$, so will men since their chance to reach the high state is higher. Therefore, if there exists a separating equilibrium, it is such that $\alpha_{w}>\alpha_{m}=0$ and $\beta_{m}>\beta_{w}$.

Let us now proceed one step further by showing that there is no separating equilibrium in this game, implying that $\alpha_{m}=\alpha_{w}=0$.

Lemma 2 The equilibrium is pooling and $\alpha_{m}=\alpha_{w}=0$.

Suppose, still, that a separating equilibrium satisfying lemma 1 exists and that men are indifferent between both contracts whereas women prefer their contract. Then the principal could decrease transfers to women such that both genders still separate on two different contracts and incentives are kept unchanged. Such a reasoning does not apply when women are indifferent since $\alpha_{m}$ is already set at 0 . Therefore, a separating equilibrium must be such that women are indifferent to both types of contract whereas men (weakly) prefer the contract $\left(0, \beta_{m}\right)$.

Let us denote $e_{i}^{w}$ the effort of an agent of type $i$ when choosing the contract $\left(\alpha_{w}, \beta_{w}\right)$ and $e_{i}^{m}$ the effort when choosing the contract $\left(0, \beta_{m}\right)$. Then, women are indifferent to both contracts and we have

$$
\alpha_{w}+p\left(e_{w}^{w}, k_{w}\right)\left(\beta_{w}-\alpha_{w}\right)-c \frac{\left(e_{w}^{w}\right)^{2}}{2}=p\left(e_{w}^{m}, k_{w}\right) \beta_{m}-c \frac{\left(e_{w}^{m}\right)^{2}}{2}
$$


In such a setting, it is straightforward to see that men will always self select on the contract designed for them. That is

$$
\alpha_{w}+p\left(e_{m}^{w}, k_{m}\right)\left(\beta_{w}-\alpha_{w}\right)-c \frac{\left(e_{m}^{w}\right)^{2}}{2}<p\left(e_{m}^{m}, k_{m}\right) \beta_{m}-c \frac{\left(e_{m}^{m}\right)^{2}}{2} .
$$

The principal will then aim at maximizing his profit under constraints (12), $\alpha_{w} \geq 0$, and $\beta_{w} \geq \alpha_{w}$. Denote $\lambda, \mu$, and $\nu$, the Lagrange multipliers associated to the constraints (12), $\alpha_{w} \geq 0$, and $\beta_{w} \geq \alpha_{w}$, respectively. Formally, writing the Lagrangian and solving the program while maximizing with respect to $\alpha_{w}$ and $\beta_{w}$, we get the following first order conditions

$$
\begin{aligned}
\frac{\partial L}{\partial \alpha_{w}}= & \left.-1-\frac{k_{w}}{c}\left(a_{1}+a_{2} \rho\right)^{2}\left(\Delta V-\left(\beta_{w}-\alpha_{w}\right)\right)+a_{3} \rho+\frac{k_{w}}{c}\left(a_{1}+a_{2} \rho\right)^{2}\left(\beta_{w}-\alpha_{w}\right)\right) \\
& +\lambda\left[1-a_{3} \rho+\frac{k_{w}^{2}}{c}\left(a_{1}+a_{2} \rho\right)^{2}\left(\beta_{w}-\alpha_{w}\right)\right]+\mu-\nu=0 \\
\frac{\partial L}{\partial \beta_{w}}= & \frac{k_{w}}{c}\left(a_{1}+a_{2} \rho\right)^{2}\left[\Delta V-\left(\beta_{w}-\alpha_{w}\right)\right]-a_{3} \rho-\frac{k_{w}}{c}\left(a_{1}+a_{2} \rho\right)^{2}\left(\beta_{w}-\alpha_{w}\right) \\
& +\lambda\left[a_{3} \rho+\frac{k_{w}^{2}}{c}\left(a_{1}+a_{2} \rho\right)^{2}\left(\beta_{w}-\alpha_{w}\right)\right]+\nu=0
\end{aligned}
$$

which directly implies that $\lambda+\mu=1$. First, note that it must be the case that $\nu=0$, otherwise $\beta_{w}=\alpha_{w}$ so that women do not exert effort.

Now, two cases have to be considered. First, if $\mu>0$, then $\alpha_{w}=0$. Second, if $\mu=0$, then $\lambda=1$. In such a case, the first-order conditions $\frac{\partial L}{\partial \alpha_{w}}=0$ and $\frac{\partial L}{\partial \beta_{w}}=0$ are equivalent to

$$
\beta_{w}-\alpha_{w}=\frac{\Delta V}{2+k_{w}}
$$

Substituting $\beta_{w}-\alpha_{w}$ by its expression in the profit of the principal, it is straightforward that this profit is a decreasing function of $\alpha_{w}$. Hence, the principal chooses $\alpha_{w}=0$.

It follows that in all cases, the principal chooses $\alpha_{w}=0$, implying that there is no separating equilibrium in which both types of agents are employed.

It is finally obvious that the principal can never exclude one type by offering a single contract since both genders are better off exerting some effort than remaining unemployed. The optimal contract is then pooling.

It now remains to derive the structure of payments in the optimal contract. In a pooling equilibrium, the principal maximizes

$$
V_{l}-\alpha+(\Delta V-\beta+\alpha)\left[a_{3} \rho+\left(a_{1}+a_{2} \rho\right)\left(\theta e^{*}\left(\alpha, \beta, k_{w}\right)+(1-\theta) e^{*}\left(\alpha, \beta, k_{m}\right)\right)\right]
$$


for which the unique solution is $\alpha^{*}\left(\theta, k_{w}, k_{m}\right)=0$ and $\beta^{*}\left(\theta, k_{w}, k_{m}\right)=\frac{\Delta V}{2}-\frac{a_{3} \rho c}{2 X(\theta)\left(a_{1}+a_{2} \rho\right)^{2}}$

Finally, we need to verify that each gender always has an incentive to exert effort. This can be deduced from the fact that, when the agent does not exert effort, his/her utility is $\rho \beta$ whereas if he/she exerts effort, his/her perceived expected utility is $\beta\left(a_{3} \rho+\left(a_{1}+a_{2} \rho\right)^{2} \frac{\left(k_{i}\right)^{2}}{2 c} \beta\right)>a_{3} \rho \beta$ for all $i$ and triplet $\left(k_{i}, \rho, c\right)$.

\section{Proof of Proposition 5}

As mentioned in section 6 , since $k_{m}^{A}=k_{w}^{A}=1$, then for all $\theta_{A} \in[0,1], \beta^{*}\left(\theta_{A}, 1,1\right)=\beta_{A}=$ $\frac{\Delta V}{2}-\frac{a_{3} \rho c}{2\left(a_{1}+a_{2} \rho\right)^{2}}$. It follows that, if choosing project $A$, men and women exert the same effort level and their expected revenue net of effort cost is

$$
\hat{U}_{m}^{N D}(\theta, 1,1)=\hat{U}_{w}^{N D}(\theta, 1,1)=U_{A}=\beta_{A}\left(a_{3} \rho+\frac{\beta_{A}}{2 c}\left(a_{1}+a_{2} \rho\right)^{2}\right)
$$

Conversely, if choosing project B, men and women do not exert the same effort level. The effort level chosen by an agent of type $i$ is $\frac{k_{i}^{B}}{c}\left(a_{1}+a_{2} \rho\right) \beta^{*}\left(\theta_{B}, k_{w}^{B}, k_{m}^{B}\right)$. It follows that the expected revenue net of effort cost of an agent of type $i$ is

$$
\hat{U}_{i}^{N D}\left(\theta_{B}, k_{m}^{B}, k_{w}^{B}\right)=\beta^{*}\left(\theta_{B}, k_{w}^{B}, k_{m}^{B}\right)\left[a_{3} \rho+\frac{\left(k_{i}^{B}\right)^{2}}{2 c}\left(a_{1}+a_{2} \rho\right)^{2} \beta^{*}\left(\theta_{B}, k_{w}^{B}, k_{m}^{B}\right)\right]
$$

A necessary condition for women to work on both projects, in equilibrium, is that $U_{A}=$ $\hat{U}_{w}^{N D}\left(\theta_{B}, k_{m}^{B}, k_{w}^{B}\right)$. It implies that if women work on both projects, men always choose project B since $\hat{U}_{m}^{N D}\left(\theta_{B}, k_{m}^{B}, k_{w}^{B}\right)>\hat{U}_{w}^{N D}\left(\theta_{B}, k_{m}^{B}, k_{w}^{B}\right)$. Assume now that all women work on project A (i.e $\left.\theta_{B}=0\right)$. Then, it can be shown that $\hat{U}_{m}^{N D}\left(0, k_{m}^{B}, k_{w}^{B}\right)>U_{A}$. Therefore, if women choose project A, then men choose project B. Stated differently, if $U_{A}>\hat{U}_{w}^{N D}\left(0, k_{m}^{B}, k_{w}^{B}\right)$, the unique equilibrium is fully separating, i.e, $\theta_{A}^{*}=1$ and $\theta_{B}^{*}=0$. Such a condition can be rewritten

$$
k_{w}^{B}<\left[\left(\frac{U_{A}}{\beta^{*}\left(0, k_{w}^{B}, k_{m}^{B}\right)}-a_{3} \rho\right) \frac{2 c}{\left(a_{1}+a_{2} \rho\right)^{2} \beta^{*}\left(0, k_{w}^{B}, k_{m}^{B}\right)}\right]^{1 / 2} \equiv G\left(k_{m}^{B}\right)
$$

Formally, whenever $k_{w}^{B}<G\left(k_{m}^{B}\right)$, we have $\theta_{A}^{*}=1$ and $\theta_{B}^{*}=0$.

Now, $\beta^{*}\left(\theta, k_{w}^{B}, k_{m}^{B}\right)$ is a decreasing function of $\theta$ which implies that $\hat{U}_{w}^{N D}\left(\theta, k_{m}^{B}, k_{w}^{B}\right)$ is a decreasing function of $\theta$. Therefore, if $U_{A} \in\left(\hat{U}_{w}^{N D}\left(1 / 2, k_{m}^{B}, k_{w}^{B}\right), \hat{U}_{w}^{N D}\left(0, k_{m}^{B}, k_{w}^{B}\right)\right)$, there exists $\theta_{B}^{*}$ such that $U_{A}=\hat{U}_{w}^{N D}\left(\theta_{B}^{*}, k_{m}^{B}, k_{w}^{B}\right)$.

Let $F\left(k_{m}^{B}, k_{w}^{B}\right)=\hat{U}_{w}^{N D}\left(1 / 2, k_{m}^{B}, k_{w}^{B}\right)$ The equation $F\left(k_{m}^{B}, k_{w}^{B}\right)=U_{A}$ has then a unique positive solution in $k_{w}$ which, of course, is a function of $k_{m}^{B}$. Denote $H\left(k_{m}^{B}\right)$ such a solution. Given that 
$\partial F / \partial k_{w}^{B}>0$, then whenever $k_{w}^{B}>H\left(k_{m}^{B}\right)$, we have $F\left(k_{m}^{B}, k_{w}^{B}\right)>U_{A}$, and women self-select on project B, i.e., $\theta_{B}^{*}=1 / 2$. In contrast, if $k_{w}^{B} \in\left(G\left(k_{m}^{B}\right), H\left(k_{m}^{B}\right)\right), \theta_{A}^{*}=1$ and $\theta_{B}^{*} \in(0,1 / 2)$. Finally, given that $\beta^{*}\left(0, k_{w}^{B}, k_{m}^{B}\right)>\beta^{*}\left(1 / 2, k_{w}^{B}, k_{m}^{B}\right)$ and $\hat{U}_{m}^{N D}\left(\theta_{B}, k_{m}^{B}, k_{w}^{B}\right)$ is increasing in $k_{m}^{B}$, we have that $H\left(k_{m}^{B}\right)>G\left(k_{m}^{B}\right)$. This completes the proof.

\section{References}

Babcock, L., Laschever, S., 2003. Women don’t ask: negotiation and the gender divide. Princeton University Press.

Barber, B., Odean, T., 2001. Boys will be boys: gender, overconfidence and common stock investment. Quarterly Journal of Economics 116, 261-292

Beyer, S., 1990. Gender differences in the accuracy of self-evaluations of performance. Journal of Personality and Social Psychology 59, 960-970.

Beyer, S., 1999a. Gender differences in causal attributions by college students of performance on course examinations. Current Psychology 17, 346-358.

Beyer, S., 1999b. Gender differences in the accuracy of grade expectancies and evaluations. Sex Roles 41, 279-196.

Beyer, S., 2002. The effect of gender, dysphoria, and performance feedback on the accuracy of self-evaluation. Sex Roles 47, 453-564.

Beyer, S., Bowden, E., 1997. Gender differences in self-perceptions: convergent evidence from three measures of accuracy and bias. Personality and Social Psychology Bulletin 23, 157-172.

Beyer, S., Rynes, K., Haller, S., 2004. Deterrents to women taking computer science courses. IEEE Society and Technology 23, 21-28.

Blau, F., Kahn, L., 2000. Gender difference in pay. Journal of Economic Perspectives 14, 75-99. Boraas, S., Rodgers, W.M., 2003. How does gender play a role in earnings gap? An update. Monthly Labor Review 125 (3), 9-15

Census Bureau, 2004. Evidence from Census 2000 about earnings by detailed occupation by men and women. CENSR-15

Corcoran, M., Duncan, G., 1979. Work history, labor forces attachment and earning difference between the sexes. Journal of Human Resources 14, 3-20.

Cox, D., 1984. Panel estimates of the effects of career interruptions on the earning of women. Economic Inquiry 22, 386-403. 
Deaux, K., Farris, E., 1977. Attributing causes for one's own performance: the effect of sex, norms and outcome. Journal of Research in Personality 11, 59-72.

DeKeuster, M., Rynes, K., DeHeer, J., 2004. The temporal stability of gender differences in MIS students.Proceedings of the Tenth Annual Meeting of the American Conference on Information Systems,1197-1204.

Eckel, C., Grossman, P., 2003. Sex and risk: experimental evidence. Handbook in Ecperimental Economics, North-Holland/Elsevier Press.

Fields, J., Wolff, E., 1995. Interindustry wage differentials and the gender wage gap. Industrial and Labor Relations Review 49, 105-120.

Filippin, A., Ichino, A., 2005. Gender wage gap in expectations and realizations. Labour Economics $12,125-45$.

Francois, P., 1997. Gender discrimination without gender difference: theory and policy responses. Journal of Public Economics 68, 1-32.

Francois, P., Van Ours, J., 2000. Gender wage differentials in a competitive labor market: the household interaction effect. CEPR Discussion paper 2603.

Goldin, C., 2002. A pollution theory of discrimination: male and female differences in occupations and earnings. NBER Working paper 8985.

Gneezy, U., Nierdele, M., Rusticchini, A., 2003. Performance in competitive environments: gender differences. Quarterly Journal of Economics 118, 1049-1074.

Graddy, K., Pistaferri, L., 2000. Wage differences by gender: evidence from recently graduated MBAs. Oxford Bulletin of Economics and Statistics 62, 837-854.

Gronau R., 1973a. The effect of children on the housewives' value of time. Journal of Political Economy 81, 168-1999.

Gronau R., 1973b. The infrafamily allocation of time: the value of housewives' time. American Economic Review 63, 634-652.

Johnson, G., Solon, G., 1986. Estimates of the direct effect of comparable worth policy. American Economic Review 76, 1117-1125.

Killingsworth, M., 1987. Heterogeneous preferences, compensating wage differentials, and comparable worth. Quarterly Journal of Economics 102, 727-742.

Kuhn, P., 1993. Demographic group and personnel policy. Labour Economics 1, 49-70. Lazear, E., Rosen, S., 1990. Male-female wage differentials in job ladders. Journal of Labor Economics 
8, 106-123. Lundeberg, M.A., Fox, P.W., Puncochar, J., 1994. Highly confident, but wrong: Gender differences and similarities in confidence judgments. Journal of Educational Psychology 86 (1), 114-121.

Meehan, A., Overton, W. F., 1986. Gender differences in expectancies for success and performance on Piagetian spatial tasks. Merrill - Palmer Quarterly 32, 427-441.

Milgrom, P., Oster, S., 1987. Job market, market forces, and the invisibility hypothesis. Quaterly Journal of Economics 102, 453-476.

Mincer, J., Ofek, H., 1982. Interrupted work careers: depreciation and restoration of human capital. Journal of Human resources 17, 3-24.

Mincer, J., Polachek, S., 1974. Family investments in human capital: earning of women. Journal of Political Economy 82, 76-108.

Niederle, M., Vesterlund, J.,2007. Do women shy away from competition? Do men compete too much? Quarterly Journal of Economics 122, 1067-1101.

O'Neill, J., 2003. The Gender wage gap, circa 2000. American Economic Review 93(2), 309-314 Polachek, S., 1981. Occupational self-selection: a human capital approach to sex differences in occupational structure. Review of Economics and Statistics 62, 60-69.

Prince, M., 1993. Women, men and money styles. Journal of Economic Psychology 14, 175-182. Reilly, K., Wirjanto, T., 1999. Does more mean less? The male/female wage gap and the proportion of females at the establishment level. Canadian Journal of Economics 32(4), 906-929. Rothschild, M., Stiglitz, J., 1982. A model of employment outcomes illustrating the effect of the structure of information on the level of distribution of income. Economics Letters 10, 231-236. The Economist (US), june 12, 2004. Sexism and the city; sexual discrimination (cases of Stephanie Villaba against Merill Lynch and Company Inc.)

Tomaskovic-Devy, D., Skaggs, S., 1999. An establishment-level test of the statistical discrimination hypothesis. Work and occupations 26, 422-445. 